how to examine each part and how to diagnose soft tissue orthopædic lesions. His account of pathology is often controversial and none the worse for that. His methods of examination are meticulous and detailed, and no reader, however skilled, can fail to benefit from their study. The appendix on statistical analysis is much too short and no account is given of methods of case selection nor the criteria by which the results are assessed; this is a pity for unless the author devotes the same clinical thoroughness to evaluating results which he applies to clinical methods he cannot hope to convince the sceptics.

Many orthopædic surgeons will disagree with many of the statements in this book, but all of them will enjoy reading it and all will learn a lot from it. To every doctor interested in physical medicine (and in this age of discs this must include all general practitioners), and to every physiotherapist who treats orthopædic disorders the book is essential.

\section{Neurological Examination in Clinical Practice}

Edwin R. Bickerstaff. Pp. $x+357$, illustrated. Oxford: Blackwell Scientific Publications. I963. 50 .

This excellent book sets out in clear and precise detail the method of examination of the nervous system. This might be thought to have resulted in a somewhat dull recitation of instructions. This is far from being the case. The author has drawn on a wide clinical experience in order to indicate throughout the purpose of each test and how it can lead to a final diagnosis. Not only are details of the clinical examination given but also the proper use of such facilities as neuroradiology, electroencephalography, electromyography and otological tests is indicated. The book is so thorough in most fields that it is a pity that the details of cystometry are insufficient for an inexperienced person to be able to undertake it. Methods and rates of filling are omitted and a diagram of the apparatus would have been helpful.

The illustrations are of high standard, the production excellent and the book can be strongly recommended.

\section{Textbook of the Fundus of the Eye}

A. I. Ballantyne, Ll.D., M.D., F.R.F.P.S., and I. C. Michaelson, F.R.F.P.S., D.O.M.S., PH.D. Pp. xix + 520, illustrated. Edinburgh and London: E. \& S. Livingstone. 1962. £7.

This textbook is a welcome and valuable addition to the present selection of textbooks on the fundus oculi. The present form is largely attributable to Professor Michaelson, who since the death of Professor Ballantyne in 1953 has carried on with the work single-handed. The volume is made up of just over 500 pages, which includes 600 excellent illustrations, and these will partly explain the high price of the book. This factor will also serve to limit this largely for use as a reference book. The text is clear and simply written, the subject matter is interesting and comprehensive and every chapter is followed by a considerable reference section.

The opening chapters describe the means available for the investigation of the fundus by ophthalmoscopy, ophthalmodynanometry and electroretinography. The following chapters survey the vast realm of retinal vascular pathology and the feature of these chapters is the correlation of the ocular manifestations in the light of the disease as a whole, which is well demonstrated in the chapter on diabetes, where the close relationship of the retinopathy and the Kimmelstiel-Wilson syndrome is considered. Furthermore, the text is enhanced by excellent photomicrographs of the pathological changes. The insertion of a section on the treatment of hypertension which is outmoded and in parts inaccurate seems unnecessary in this book. Fundal manifestation of systemic diseases are considered in relation to the blood dyscrasias, the collagen diseases, the phakomatoses and the lipoidoses. These chapters would be of particular interest to the physician for both the material presented and the bibliography, but it is also valuable to know that here is a book where such topics as the association of colloid bodies in polyserositis or angioid streaks in Paget's disease can be found. The final chapters include a useful section on the clinical value of the electroretinogram, and the vitreous, choroid, and optic nerve are considered and the high standard of the rest of the book is maintained.

In conclusion, it may be said that this is a valuable and important book not only for the ophthalmologist, but for the physician as well, and is strongly recommended as being one of the best books on this subject.

\section{Diseases of the Nervous System}

Sir Francis Walshe. Tenth edition. Pp. xii + 381, illustrated. Edinburgh and London: E. \& S. Livingstone. 1963. 35 s.

This well-known textbook needs no introduction and little commendation; the appearance of the tenth edition is testimony enough to its value and popularity. The sub-title declares that the diseases are 'described for practitioners and students' and this surely is the secret of the book's success, for few can rival it in descriptions which make diseases spring to life and create mental pictures which never become blurred.

Although a valiant effort has been made to give therapeutics a place more in keeping with its present status in neurology, it cannot be said to have been wholly successful. Too much space is devoted to warnings against the dangers of over-treatment (which is hardly a besetting sin of neurologists) and too little and too imprecise information is given about therapy which can and should be employed. Nevertheless, the book remains one which no one interested in neurology can be without.

Therapist-Patient Expectancies in Psychotherapy

Arnold P. Goldstein. Pp. xvi + i4r. Oxford, London, New York and Paris: Pergamon Press. 1962. 30s.

It is said that doctors are at last becoming aware once more of the possible major significance of the doctor-patient relationship as an intervening variable affecting their management and care of patients. To those interested in this subject this book presents a study of the relationship from one particular viewpoint. The author attempts to evaluate the importance to therapeutic outcome of the treatment expectancies of the therapist and patient in psychotherapy. The subject matter is presented directly and clearly, and wide and useful reference is made to the relevant literature. The author's views appear particularly appropriate in his criticism of the concept of spontaneous remission. This particular chapter serves to highlight the possible importance of the doctor-patient relationship. The chapter on the placebo effect, which also contains some useful references to the phenomena of transference cure, effectively embodies the author's approach.

This whole research field is a particularly exciting one, since it involves the study of human relationships. Research at the level of patient expectancy will probably be complicated by the fact that the human quality of 
anticipation has its realistic, cultural and neurotic determinants. The extent to which any one of these determinants contributes to the expectancy level probably varies considerably between social groups and personality types as well as longitudinally in one person. Carefully controlled studies are therefore necessary. The other major problem is that of measuring patients' expectancies. The author is aware of these difficulties and he presents a concise and fair exposition of the problems to date. The book carries a message for all doctors and is at the same time a stimulating source of information for interested research workers.

\section{Interhemispheric Relations and Cerebral Dominance}

Editor: Vernon B. Mountcastle. Pp. 294. Baltimore: The Johns Hopkins Press. 1962. Price not stated.

Although the conference, the proceedings of which are presented in this book, was concerned with the question: 'Why do we have two brains', only Professor $\mathrm{J}$. Z. Young in a stimulating and erudite contribution made any serious attempt to answer it. The remaining contributors contended themselves with the less ambitious task of presenting evidence of how the two hemispheres interact. They discussed the 'how' rather than the 'why'. Their contributions, nevertheless, make interesting reading; psychologists will value especially the contributions of Myers, Ettlinger and Downer on visual and somato-sensory integration; clinicians will enjoy Hecaen's account of his statistical assessments of the clinical symptomatology of lesions of each side of the brain. But as Young says in his admirable summing-up of the conference, the problem of cerebral dominance 'will demand the joint efforts of many generation s of scientists' before it yields its secret.

\section{Handbook of Pediatrics}

H. K. Silver, C. H. Kempe and W. B. Bruyn. Fifth edition. Pp. 62. Los Altos, California: Lange Medical Publications. 1963. \$4.

This American Handbook was first published in 1955 and has now entered its fifth edition. Three foreign language versions exist and two more are in preparation. The stated aim of the authors is to supplement the standard textbooks with ' a concise and readily available digest of the material necessary for the diagnosis and management of pediatric disorders '.

Most topics of pædiatric interest are covered adequately. Some features of the publication are commendable for example the numerous tables of information concerning growth, performance and pathology, also the diagrams illustrating some pædiatric procedures. The prominence given to pædiatric emergencies and to the management of poisoning in children is praiseworthy. Inevitably many American terms are used in the text, especially in the nomenclature of drugs. Some suggestions in the text are surprising, extreme examples are the instillation of $1 \%$ silver nitrate into the eyes of the newborn and the examination of frozen sections of umbilical cord for evidence of vasculitis. The description of a 'battered child syndrome', seems to be unnecessary and the statement that the complete examination of a child will include a routine W.R. will seem unusual in this country.

Although this is a handbook, nevertheless it comprises 602 pages of small type and is devoid of illustration apart from the diagrams to which reference has been made. The authors have succeeded in providing a portable and comprehensive source of information; they have not, however, been concise.
The Obstetrician, Anæsthetist and the Pædiatrician in the Management of Obstetric Problems

Edited by Trevor BarnetT and John JoYCE Foley. \$ Pp. xiii +188 , illustrated. Oxford, London, New York and Paris: Pergamon Press (Symposium Publications Division). 1963. 50s.

This is a nicely produced book and must serve as splendid record for those who attended the conference. However, like all such records of the spoken word, the $\overline{\bar{O}}$ English has suffered and, in some cases, the meaning is $\frac{\bar{\rho}}{\partial}$ not clear.

A number of the leading Obstetricians in the country took part and among them, Professor Duncan's remarks on domiciliary midwifery were pre-eminent. Professor $\vec{\theta}$ Donald's talk must have been a pleasure to listen to, $?$ when he spoke of resuscitation of the newborn.

Many speakers appear to be carried away by their $\vec{\omega}$ enthusiasm for their own methods and, where factual $\frac{\partial}{\partial}$ evidence was brought forward to support their claims, the conclusions were often mathematically faulty. A maternal mortality rate of $0.05 \%$ in the Dublin district could hardly be considered evidence of a successful selection of cases of good midwifery practice, but, $\vec{v}$ perhaps, there is a misprint here.

The discussion on resuscitation of the newborn was a reminder of the zeal shown for intra-gastric oxygen a $\vec{\sim}$ few years ago and the answer to this problem surely, is ${ }^{\prime}$ better obstetrics with no treatment required for an 윽 asphyxiated baby.

The book may be read with profit by independent $\vec{z}$ Obstetricians but could not be recommended for a $Z$ student or postgraduate, as the views expressed are often $\widehat{\mathbb{D}}_{3}$ contradictory.

The general impression may give rise to the view that the care of the mother and her baby is passing from the Obstetrician to the Anæsthetist and Pædiatrician.

The Anatomical Foundation of Neruoradiology the Brain

McClure Wilson. Pp. $\mathrm{x}+$ 239, illustrated. London: J. \& A. Churchill. r963. £4 ros.

The teaching of anatomy to undergraduates is governed by the need to provide a wide view of the whole subject $\frac{}{\Phi}$ and to make the general principles familiar. When the graduate decides to specialize he then has to go back to $\overrightarrow{\overrightarrow{0}}$ basic anatomy and physiology, and learn again in more detail those parts which are appropriate. This is particularly true of the anatomy of the brain.

Dr. McClure Wilson has provided the necessary review and additional details of cerebral and cerebrovascu- $\bar{\partial}$ lar anatomy needed by those who are studying neuro- 3 radiology. There are chapters on the superficial an!tomy $\bar{\sigma}$ of the brain, the venticular system, the subarachnoid 3 space and the arterial and venous systems, among others. It is an admirable, lucid, and accurate account of the struc- $O$ tures demonstrated by various radiological techniques, and ought to be read by any person learning the inter-응 pretation of cerebral angiograms and air studies. In this respect, it is a more valuable work of reference than $\frac{7}{O}$ the standard anatomical textbooks, in which the clinically important features are often obscured by detail or $N$ omitted altogether. The reproduction of x-rays is ex-s cellent, but some of the line drawings are a bit too freely $N$ diagrammatic. The index is satisfactory.

This book can unreservedly be recommended not $\omega$ only to radiologists, but also to neurological and neurosurgical house staff whose final ambitions do not demand more detailed neuroanatomy, and should be available to all those who find the anatomy of the brain a land of $\mathbb{S}$ mystery. It is to be hoped that a further volume on the? skull and spine will soon appear. 